\title{
IMPACT OF MULTILINGUALISM ON THE EARLY CHILD DEVELOPMENT
}

\author{
Iftikhar Shafiq \\ MPhil sociology \\ Dr. Naima Saeed. \\ Assistant Professor University of Karachi
}

\begin{abstract}
There is certainly found an instrumental role of primary language in early childhood development. The domains of child development and early learning are discussed in different terms and categorized in different ways in the various fields and disciplines that are involved in research, practice, and policy related to children from birth through age. The primary language has significant role for learning process in early childhood development. Keeping its importance, it is included in National Education Policy 2009. This is very general that many children speak a home language that differs from the language of instruction in education programs. Research confirms that children learn best in their mother tongue as a prelude to and complement of bilingual and multilingual education. Whether children successfully retain their mother tongue while acquiring additional languages depends on several interacting factors. This further help the students in early grades that students acquire much knowledge and easily learn in primary language. The most significant part of schooling is the early education or early development of child related to their social and educational problems, the role of primary language cannot be ignored because such like Quetta city, the majority of the students learn education in their secondary language, the medium of
\end{abstract}


instruction in private schools is mostly English and Urdu but in public school the Urdu is used commonly. However the large number of population lives in Quetta they speak their first language as Pashto, Balochi, Brahui, and Hazargi, but less number of students speak Urdu as first or primary language, not only in Quetta but also in all over the province the education system is not good enough to provide quality education to the students, the public and private schools are providing education in province but all of them lack the services

Key words: Child Development, Primary Language, Policy, Practice, Bilingual ,Multilingualism, Mod of Instruction.

\section{INTRODUCTION.}

Different studies indicate that having a strong mother tongue foundation leads to a much better understanding of the curriculum as well as a more positive attitude towards school, so it's vital that children maintain their first language when they begin schooling in a different language.

It is observed that when children develop their mother tongue, they are simultaneously fostering a whole host of other essential skills, such as critical thinking and literacy skills. It is these skills that they take with them into formal education, and research tells us that any skills and concepts gained in the learner's home language don't have to be re-taught when they transfer to a second language. For example, if a child has developed the ability to guess the meaning of a word through its context, or to infer meaning by reading between the lines, these skills are easily transferred when they begin studying in a second language. It is much harder, however, to teach these abstract skills directly through a second language. 
It's also well known that a strong mother tongue foundation equips children with the skills they need to learn additional languages, allowing them to transfer their understanding of the structure of language to several new languages. The intuitive understanding of grammar that develops when children learn their first language can easily be passed on to other languages. With multilingualism becoming an increasingly sought-after attribute within the workplace, this advantage cannot be overstated. Globalization and increased co-operation between nations mean that, in many organizations, it has become a requirement to have language skills in addition to being a specialist within a particular field.

It is true that language and mother tongue also play a huge role in the development of personal, social and cultural identity. Children with a strong foundation in their first language often display a deeper understanding of themselves and their place within society, along with an increased sense of wellbeing and confidence. Naturally, this flows down into every aspect of their lives, including their academic achievement.

This is, of course, one of the reasons why bilingual education systems are growing in popularity around the world and many international schools are focusing their resources on establishing strong mother tongue programs. Parent workshops outlining the importance of the mother tongue are becoming increasingly popular, because many parents mistakenly believe that they should only speak to their children in the school's language of instruction, often contributing to children not gaining complete fluency in either their first or second language. An international researcher quotes that in Cambodia, for example, our EAL (English as an Additional Language) specialists regularly invited parents into school for evening workshops, where they outlined research showing how children learn languages, discussed the 
school's teaching methodology for language learning, and, most importantly, explained the importance of a strong mother tongue foundation and the vital role that parents play in developing and maintaining this.

As Irina Bokova, UNESCO Director General said, "Mother languages in a multilingual approach are essential components of quality education, which is itself the foundation for empowering women and men and their societies."

Presently, we are living in a time of unprecedented travel, with technological advances and globalization offering more and more people the opportunity to explore and live in cultures that are not their own. International schools have been established for decades now and are rapidly growing in popularity, particularly amongst local populations, as they offer easier access to higher education opportunities around the world. As a consequence, the number of children learning in a language other than their mother tongue is growing rapidly.

Researches show that having a strong mother tongue foundation leads to a much better understanding of the curriculum as well as a more positive attitude towards school, so it's vital that children maintain their first language when they begin schooling in a different language.

Language and mother tongue also play a huge role in the development of personal, social and cultural identity. Children with a strong foundation in their first language often display a deeper understanding of themselves and their place within society, along with an increased sense of wellbeing and confidence. Naturally, this flows down into every aspect of their lives, including their academic achievement.

Language is deeply connected to notions of culture and identity, and the language children are taught in can often reflect broader societal 
inequalities. For example, in many countries the ethnic majority population, which often speaks the dominant language, enjoy better learning outcomes than minority groups that speak other languages. Inequality in education is actually increasing - including for those marginalized by language. When pre-existing barriers to education, such as poverty, or living in rural areas, combine with schooling in an unknown language, children are less likely to make it to school, and if they do, are less likely to stay there. Conversely, some education systems favor using national or 'global' languages based on the belief that this will give children a competitive advantage in later life. Research shows, however, that bilingual education which includes the mother tongue can lead to improved attainment levels more generally.

Being taught in a known language is a key component of quality education for all learners - from the very early stages right through to adulthood. Early education in the mother tongue can prepare children for school and foster foundational skills, such as literacy and critical thinking, which are proven to significantly increase learning later on. Likewise, mother tongue adult literacy programs of good quality need to be available in order to improve adult literacy levels, particularly in developing countries; around 757 million adults cannot read or write a simple sentence, and a quarter of those live in sub-Saharan Africa - one of the most linguistically diverse regions in the world.

\section{IMPACT OF MULTILINGUALISM ON EARLY CHILD DEVELOPMENT}

Children's primary language creates the powerful basis for learning and future life, and it attracts the students to be admitted or enrolled in school and to be active in their education activities, the students tend to develop 
good thinking and educational skills, mother tongue plays a significant role in the early development of child, because primary language as medium of instruction can solve several educational problems Gupta, A. F. (1997).

The primary language as medium of instruction in some situations may not be desirable however in monolingual societies it is not difficult to implement primary language as medium of instruction but in many multilingual societies it is not easy to implement primary language as medium of instruction in schools because, in a class there can be different multilingual and multicultural students, where it can never be easy to follow one language or different languages as medium of language in a one class, in such societies the secondary language is preferred as medium of instruction in educational institutes, Bamgbose, A. (1976). In many multilingual and multicultural countries such as Pakistan and in certain policy decisions which is to be made that is the choice of the language which is to be used as medium of instruction. Whatever policy or choice is made that is to take into consideration the role of the students primary language. Bamgbose, A. (1984). Pakistan does not have uniformity in the medium of instruction and in syllabus, the provinces have their own syllabus where public and private educational institutes have their own syllabus which is mostly designed in English language however the students hardly understand English language in Pakistan.

Same is the situation in Quetta city as it is multilingual and multicultural city where Pashtu, Brahvi, Balochi, Hazargi, Panjabi, are the major languages, the aim of this research was to identify the impacts of primary language on the early child development in Quetta city.

\begin{tabular}{l|l|l} 
Languages spoken by & Frequency & Percentage \\
the Respondents & &
\end{tabular}




\begin{tabular}{c|c|c} 
Pashtu & 79 & $26 \%$ \\
\hline Brahui & 62 & $21 \%$ \\
\hline Balochi & 28 & $10 \%$ \\
\hline Hazargi & 37 & $12 \%$ \\
\hline Urdu & 30 & $10 \%$ \\
\hline Panjabi & 42 & $14 \%$ \\
\hline Sindhi & 22 & $7 \%$ \\
\hline Total & 300 & $100 \%$
\end{tabular}

The above table shows the languages spoken in Quetta city, it also shows that the city is full of different ethnic groups are residing in it, which directly influences the literacy and education of city, the education sector in Quetta city needs more better plaining and policy to improve its early child development.

As it is mentioned above the Quetta is the multilingual and multicultural city where different languages and cultural are adopted. The following table shows the respondents can speak second language other than their primary languages.

\begin{tabular}{|c|c|c|}
\hline $\begin{array}{l}\text { Different Languages spoken } \\
\text { by the respondents }\end{array}$ & Frequency & Percentage \\
\hline Monolingual & 210 & $70 \%$ \\
\hline Bilingual & 71 & $24 \%$ \\
\hline Multilingual & 19 & $6 \%$ \\
\hline Total & 300 & 100.0 \\
\hline
\end{tabular}

The above table shows that the two third of the respondents can speak single language or can speak just their mother tongue where it is not easy for the respondents to get education in secondary language such as Urdu and English, the respondents who are having their education from public 
educational institutes are mono lingual and their English language is week as compare to private educational institutes.

The education sector is not performing its duties as schools lack all the basic facilities including electricity and natural gas, the health and hygiene facilities are not provided in the schools, the lack of curriculum and co-curriculum activities are found in all schools of Quetta city, the scientific labs are not well equipped,

\section{RECOMMENDATION AND SUGGESTIONS.}

The social, physical and emotional development of children has a direct impact on their personality, it is most important to invest on child at his early age, however the primary language also has direct impact on early child education, The current study shows that the education system in Quetta or even in all province needs to be improved because it lacks all the modern ways of learning and teaching, early child education or development is the base for higher educations but the situation is changed as compare to other developed countries because it was observed in this study that the higher education is given more priority than the early child education, the syllabus, curriculum and co-curriculum activities are not normally practiced in the schools, the schools mostly lack all the basic facilities related to early child development, the children lack all the basic material related to early child development, the modern teaching techniques to be implemented in the all public and private schools, the teaching trainings to be conducted regularly related to the early child development,

The all five areas of early child development should be focused in all public and private schools, such as social and emotional, physical, approached to thinking, learning and communication and languages, the 
schools administration or the teacher who deal with early child development should manage such activities for babies, toddlers and preschoolers, and to find online or local resources for early child educators. There is multilingual and multicultural society in Quetta city, but in major part of the Quetta city there are monolingual societies, where the authorities can implement new modern techniques of teaching such as the mod of instruction should be the primary language or the mother tongue of the respondents. The primary langue should be considered as mod of instruction in all the schools of Quetta and also on province level, the especial activities to be designed for the early child educators, the syllabus and other learning books should be translated into the primary language of children, the children at early age should be given all the necessary environment to improve the educational skills of children. 


\section{REFERENCES}

Mustard, J. F. (2007). Experience-based brain development: Scientific underpinnings of the importance of early child development in a global world. Early child development: from measurement to action. Washington DC, The World Bank, 43-86.Haque, A. R. (1982). The position and status of English in Pakistan. World Englishes, 2(1), 6-9.

Landau, B., Smith, L. B., \& Jones, S. S. (1988). The importance of shape in early lexical learning. Cognitive development, 3(3), 299-321.Ghayur, S., \&Burki, A. A. (1992). Combating Unemployment in Pakistan [with Comments]. The Pakistan Development Review, 31(4), 1255-1266.

Hathaway, R. M. (2005). Education Reform in Pakistan: Building for the Future. Woodrow Wilson International Center for Scholars. One Woodrow Wilson Plaza, 1300 Pennsylvania Avenue NW, Washington, DC 200043027.

Gupta, A. F. (1997). When mother-tongue education is not preferred. Journal of Multilingual and Multicultural Development, 18(6), 496-506.

Bamgbose, A. (1984). Mother-tongue medium and scholastic attainment in Nigeria. Prospects, 14(1), 87-93.

Bamgbose, A. (1976). Mother Tongue Education: The West African Experience. 
Knox, A. (1992). Influences on career choice: the responses of ethnicminority and ethnic-majority girls. British Journal of Guidance \& Counselling, 20(2), 193-204.

Siann, G., Knox, A., Thornley, E., \& Evans, R. (1990). Parents, careers and culture: the view of ethnic-minority and ethnic-majority girls. British Journal of Guidance \& Counselling, 18(2), 156-169.

Falaye, F. W., \& Adams, B. T. (2008). An assessment of factors influencing career decisions of in-school youths. Pakistan Journal of social sciences, 5(3), $222-225$.

Hue, M. T. (2010). The challenges of making school guidance culturally responsive: Narratives of pastoral needs of ethnic minority students in Hong Kong secondary schools. Educational Studies, 36(4), 357-369.

Soliman, A. M. (1991). The role of counseling in developing countries. International Journal for the Advancement of Counselling, 14(1), $3-14$. 